\title{
Seroprevalence of Human Immunodeficiency Virus and Syphilis Infections among Patients Attending the STD, Gyn. and Obs., ANC Clinics of Northern India: Observations from Seven Rounds of Sentinel Surveillance (1998-2004)
}

\author{
Tahziba Hussain, K.K.Kulshreshtha, V.S.Yadav, U.Sengupta and V.M.Katoch \\ HIV/AIDS UNIT, National JALMA Institute for Leprosy \& Other Mycobacterial Diseases \\ Indian Council of Medical Research, Tajganj, Agra-282001, India
}

\begin{abstract}
The data of HIV sentinel surveillance, i.e., National Annual Sentinel Surveillance (NASS) carried out under the aegis of National AIDS Control Organisation (NACO) of seven rounds revealed that the prevalence of HIV infection is less among the attendees of STD, Obs.\& Gyn., Antenatal ( ANC) clinics whereas that of Syphilis is high. This study was carried in order to assess the prevalence levels of infections with HIV and Syphilis as biological markers of risk among the patients attending the STD clinics, Obs. \& Gyn.OPD, Antenatal (ANC) clinics of different District Hospitals of Uttar Pradesh. Unlinked anonymous coded sera samples received from 3978 patients during a period of 4 months, every year, over a period of 7 years, were screened for HIV and Syphilis infections. Of the 3978 coded sera samples, $42(1.06 \%)$ were found to be positive for antibodies to HIV-1/2 and 322 $(8.09 \%)$ were reactive to VDRL. The results revealed that patients attending these clinics, harbour HIV infection, which would otherwise remain undiagnosed in the absence of screening. While some of the variables, viz., sex, age-group and occupation were significant factors in the HIV-positivity, others like literacy status, locality, migration and even the presence of different STDs were not found to influence the HIV-positivity, significantly.
\end{abstract}

Key words: Sentinel surveillance, HIV, STDs, trends, seroprevalence

\section{INTRODUCTION}

Chronic infections with Human Immunodeficiency Virus (HIV) and Sexually transmitted diseases (STDs) are public health problems of major significance in most parts of the world. The incidence of acute STDs is high in many countries, including India although the precise magnitude of the problem is still not clear. Failure to diagnose and treat STDs at an early stage results in serious complications and sequelae, including infertility, fetal wastage, ectopic pregnancy, cancer and death. Among the blood-borne viruses transmissible through parenteral route, blood transfusion as well as sexual intercourse, HIV-1/2 and Syphilis are important and have several implications. Not only do they establish asymptomatic persistent infections with occasional sequelae, but they also cause significant morbidity and mortality when transmitted through transfusion of blood and blood products ${ }^{[1]}$. Many risk behaviours as well as the routes of transmission are identical to those for HIV and other STDs ${ }^{[2]}$. Early diagnosis and effective treatment of STDs, especially those which cause ulcers and blood-borne infections are an important strategy for prevention of HIV transmission. Globally, the HIV sentinel surveillance system has been recognized as an optimal mechanism to monitor trends of HIV infection in specific high risk groups as well as low risk groups ${ }^{[3]}$. In India, high risk of populations include patients attending STD clinics, MSM clinics, drug de-addiction centres while mothers attending antenatal clinics are regarded as a proxy for the general population. This study is a retrospective analysis of the seven rounds of Sentinel surveillance which was carried out in the Voluntary Confidential, Counselling \& Testing Centre (VCCTC) at this Institute. This Centre was involved in the screening of samples for HIV and VDRL. The objectives of the Sentinel surveillance were to assess the prevalence levels of HIV and Syphilis infections, as biological markers of risk among the patients attending the sentinel sites (STD, Gyn. \& Obs. and ANC clinics). This study is the first of its kind in this region of the country.

Study design: The study design was followed according to the guidelines and operational procedures for sentinel surveillance as well as the method of testing, i.e., Unlinked anonymous testing, which were formulated by the National AIDS Control Organisation (NACO). The rationale for choosing sentinel sites in these clinics is that the samples from the respective risk groups, attending the clinic-based settings could be collected at regular intervals. Sites with $75 \%$ coverage of desired sample size were included for analysis.

Corresponding Author: Tahziba Hussain, Ph.D., HIV/AIDS UNIT, National JALMA Institute for Leprosy \& Other Mycobacterial Diseases, (Indian Council of Medical Research) Tajganj, Agra-282001, India, Tel: + 91056223317514, Ext. 287, Fax: +9105622331755 
Sentinel sites are located in precisely each category among the clinics cited, so that blood samples are accessed both from high risk groups as well as from low risk groups. The rationale for choosing sample size is that during this period, i.e., four months, a predetermined number of samples could be collected, from the various groups [STD clinic and Gyn.\&Obs. clinic attendees, considered to be high-risk groups whereas ANC clinic attendees are considered to be low risk group]. The sample size and sampling period were decided in the beginning of the sentinel surveillance, each year. Consecutive sampling continued until the pre-determined sample size was reached or predetermined sampling period was over. Although due to operational difficulties, it became difficult to meet the target in each year or to obtain the pre-determined sample size.

The inclusion criteria for ANC cases was all antenatal women attending the ANC clinic for the first time during the sampling period and that for STD patients was male patients presenting with either Genital ulcers or / warts or / urethral discharge and female patients presenting with either Genital ulcers or / warts or / cervical discharge as confirmed by per speculum examination, for Gynae. OPD, new STD patients attending Gynae.OPD during the sampling period, with or without symptoms. The whole procedure is unlinked anonymous. Unlinked anonymous testing means a sample originally collected for other purpose, i.e., VDRL is tested for HIV after all information that could identify the source of blood sample are eliminated from the sample ${ }^{[4]}$. Thus, unlinked anonymous coded sera samples received from the patients attending the Sentinel sites, i.e., STD, Gyn.\&Obs. and ANC clinics were screened simultaneously for co-existing infections with HIV and Syphilis. The data of socio-demographic profile, HIV status, history of STDs and VDRL status of 3978 attendees of the Sentinel sites has been compiled in Table 1 and 2. Sentinel surveillance was carried over a period of 4 months, between August to November, every year, over a period of 7 years, from 1998 to 2004 . The sentinel sites were OPD of STD clinics, Gyn.\&Obs. Clinics and Antenatal (ANC) clinics of different District Hospitals (Agra, Etawah and Farrukhabad) of Uttar Pradesh, India. In the first year, 143 samples were collected, in the second, third and fourth year, 250 samples were collected, each year. During the first 4 years, samples from ANC clinics were not included. In the fifth year, 1315 and in the sixth year and seventh year, 873 and 897 samples, respectively were collected. During the last 3 years, 400 samples from ANC clinics were included, each year, for screening of HIV and VDRL infections.

\section{MATERIALS AND METHODS}

Sampling technique: The sampling of STD/ANC clinics and Gyn.\&Obs. clinic attendees began at the beginning of sampling period, i.e., $1^{\text {st }}$ August and continued till the end of November, every year. The blood samples, $5 \mathrm{ml}$, were drawn at the respective clinic sites, to avoid dropouts. Consecutive blood samples were collected asceptically from each survey participant, i.e., new STD patients [from STD clinics, Gyn.\&Obs. clinics of Agra) and from ANC cases attending [ANC clinic of Etawah] as well as from [STD clinics \& Gyn.\&Obs. clinics of Farrukhabad] for VDRL and HIV testing. The socio-demographic profile and the complaints at the time of testing were recorded. The number of samples actually collected were used in the study, even if less than anticipation. The sera samples, collected after centrifugation at $2500 \mathrm{~g}$, were delivered to our laboratory under strict cold chain precautions. These samples were stored at $-20^{\circ} \mathrm{C}$ until the assays were performed. The kits used for immunoassays were Genedia HIV-1/2 EIA kit (Greencross, Korea). Those found positive were confirmed by rapid (HIV Capillus latex aggregation assay, Trinity Biotech PLC, Ireland) and Rapid Spot Assay (Genelabs Diagnostics Pte. Ltd.,Singapore) and VDRL-CARBOGEN Rapid Plasma Reagin (RPR) card test / Carbon antigen for Syphilis Testing (Tulip Diagnostics(P)Ltd.,Goa, India). Positive VDRLs were confirmed by a Treponema specific test, INNO-LIA Syphilis ( Innogenetics NV, Ghent, Belgium $)^{[5]}$. Sera samples were diluted and tested according to the kit's specifications. Western blot (WB) was performed with New LAV Blot-1 (BIORAD FUJIREBIO, Japan) using the ELISA positive serum samples.

Statistical analysis: Data were analysed to see the statistical significance of association between the HIVpositive status and Sex, Age, Locality, Literacy, Occupation, period of stay, history of STDs of the attendees using Pearson's Chi-Square test. Chi-Square (trend) was used to analyse the increasing / decreasing trend of both the infections during the seven years of surveillance. The significance of difference in the proportions of HIV-positivity and VDRL-reactivty among different groups was also examined with $\mathrm{Z}$ statistics at $5 \%$ level of significance.

\section{RESULTS}

Table 1 depicts the sequential yearly data of HIV infection among the patients attending the sentinel sites (STD, Gyn. \& Obs., ANC clinics). During the first year, 143 were screened, out of which 5 (3.49\%) were found to be HIV-positive. In the second, third and fourth year, a gradual decrease 4/250 (1.6\%), 3/250 $(1.2 \%)$ and $2 / 250(0.8 \%)$, respectively in HIV infection 
Table 1: The sequential yearly screening of the HIV and syphilis infection among patients attending the Sentinel Sites: STD, Gyn.\&Obs. and ANC clinics

\begin{tabular}{|c|c|c|c|c|c|c|c|c|c|c|c|c|c|c|}
\hline \multirow[b]{3}{*}{ Year } & \multicolumn{14}{|c|}{ Sentinel Sites } \\
\hline & \multicolumn{3}{|c|}{ STD clinics } & \multicolumn{3}{|c|}{ Gyn.\&Obs. Clinics } & \multicolumn{3}{|c|}{ ANC clinics } & \multicolumn{5}{|l|}{ Total } \\
\hline & $\begin{array}{l}\text { Nos. } \\
\text { Screened }\end{array}$ & $\begin{array}{l}\text { HIV- } \\
\text { positive }\end{array}$ & $\begin{array}{l}\text { VDRL- } \\
\text { reactive }\end{array}$ & $\begin{array}{l}\text { Nos. } \\
\text { Screened }\end{array}$ & $\begin{array}{l}\text { HIV- } \\
\text { positive }\end{array}$ & $\begin{array}{l}\text { VDRL- } \\
\text { reactive }\end{array}$ & $\begin{array}{l}\text { Nos. } \\
\text { Screened }\end{array}$ & $\begin{array}{l}\text { HIV- } \\
\text { positive }\end{array}$ & $\begin{array}{l}\text { VDRL- } \\
\text { reactive }\end{array}$ & $\begin{array}{l}\text { Nos. } \\
\text { Screened }\end{array}$ & $\begin{array}{l}\text { HIV- } \\
\text { positive }\end{array}$ & $(\%)$ & $\begin{array}{l}\text { VDRL- } \\
\text { reactive }\end{array}$ & $(\%)$ \\
\hline I & 143 & 5 & 9 & - & - & - & - & - & - & 143 & 5 & $(3.49 \%)$ & 9 & $(6.29 \%)$ \\
\hline II & 150 & 3 & 9 & 100 & 1 & 8 & - & - & - & 250 & 4 & $(1.6 \%)$ & 17 & $(6.8 \%)$ \\
\hline III & 150 & 2 & 7 & 100 & 1 & 4 & - & - & - & 250 & 3 & $(1.2 \%)$ & 11 & $(4.4 \%)$ \\
\hline IV & 150 & 2 & 14 & 100 & - & 6 & - & - & - & 250 & 2 & $(0.8 \%)$ & 20 & $(8 \%)$ \\
\hline $\mathrm{V}$ & 565 & 7 & 60 & 350 & 4 & 23 & 400 & 7 & 15 & 1315 & 18 & $(1.36 \%)$ & 98 & $(7.45 \%)$ \\
\hline VI & 285 & 4 & 19 & 188 & 1 & 7 & 400 & 3 & 26 & 873 & 8 & $(0.8 \%)$ & 52 & $(5.95 \%)$ \\
\hline VII & 297 & 3 & 47 & 200 & - & 21 & 400 & 1 & 47 & 897 & 4 & $(0.33 \%)$ & 115 & (12.82\%) \\
\hline Total & 1740 & 26 & 165 & 1038 & 7 & 69 & 1200 & 11 & 88 & 3978 & 42 & $(1.06 \%)$ & 322 & $(8.09 \%)$ \\
\hline \%positivity & - & $1.49 \%$ & $9.48 \%$ & - & $0.67 \%$ & $6.64 \%$ & - & $0.91 \%$ & $7.33 \%$ & - & & & & \\
\hline
\end{tabular}

Table 2: The socio-demographic profile, HIV status and history of STDs among patients attending the Sentinel Sites: STD, Gyn.OPD and ANC clinics

\begin{tabular}{|c|c|c|c|c|c|c|c|c|}
\hline \multicolumn{2}{|c|}{$\begin{array}{l}\text { Sentinel Sites attendees } \\
(\mathrm{n}=3978)\end{array}$} & \multicolumn{2}{|c|}{$\begin{array}{l}\text { Male } \\
(\mathrm{n}=1355)\end{array}$} & \multicolumn{2}{|c|}{$\begin{array}{l}\text { Female } \\
(\mathrm{n}=2623)\end{array}$} & \multicolumn{2}{|c|}{$\begin{array}{l}\text { Total } \\
(\mathrm{n}=3978)\end{array}$} & \multirow{2}{*}{$\begin{array}{l}\text { Statistics } \\
-\mathrm{X} 2 \text { (df)P value }\end{array}$} \\
\hline Parameters & Categories & No.Sc. & HIV-P & No.Sc. & HIV-P & No.Sc. & HIV-P & \\
\hline \multirow[t]{4}{*}{$\begin{array}{l}\text { Age Group } \\
\text { (years) }\end{array}$} & $<20$ & 230 & 4 & 339 & 3 & 569 & 7 & \multirow[t]{4}{*}{$\begin{array}{l}\mathrm{X} 2(3)=11.41 \\
\mathrm{P}=0.010\end{array}$} \\
\hline & $21-29$ & 465 & 4 & 1555 & 7 & 2020 & 11 & \\
\hline & $30-44$ & 497 & 12 & 640 & 7 & 1137 & 19 & \\
\hline & $>45$ & 163 & 4 & 89 & 1 & 252 & 5 & \\
\hline \multirow[t]{2}{*}{$\begin{array}{l}\text { Marital } \\
\text { Status }\end{array}$} & Married & 1054 & 19 & 2060 & 14 & 3114 & 33 & \multirow[t]{2}{*}{$\begin{array}{l}X 2(1)=0.002 \\
P=0.963\end{array}$} \\
\hline & Unmarried & 301 & 5 & 563 & 4 & 864 & 9 & \\
\hline \multirow[t]{2}{*}{ Locality } & Urban & 1035 & 21 & 1647 & 10 & 2682 & 31 & \multirow[t]{2}{*}{$\begin{array}{l}\mathrm{X} 2(1)=0.788 \\
\mathrm{P}=0.374\end{array}$} \\
\hline & Rural & 320 & 3 & 976 & 8 & 1296 & 11 & \\
\hline \multirow[t]{4}{*}{$\begin{array}{l}\text { Literacy } \\
\text { Status }\end{array}$} & Illiterate & 260 & 4 & 1047 & 7 & 1307 & 11 & \multirow[t]{4}{*}{$\begin{array}{l}\mathrm{X} 2(3)=4.761 \\
\mathrm{P}=0.190\end{array}$} \\
\hline & Literate $\&$ till $5^{\text {th }}$ & 236 & 3 & 495 & 2 & 731 & 5 & \\
\hline & Till $12^{\text {th }}$ & 514 & 8 & 741 & 6 & 1255 & 14 & \\
\hline & Graduate $\&$ above & 345 & 9 & 340 & 3 & 685 & 12 & \\
\hline \multirow{9}{*}{ Occupation } & $\begin{array}{l}\text { Agriculture / } \\
\text { unskilled workers }\end{array}$ & 378 & 2 & 875 & 2 & 1253 & 4 & \multirow[t]{9}{*}{$\begin{array}{l}X 2(8)=16.720 \\
P=0.033\end{array}$} \\
\hline & $\begin{array}{l}\text { Truck/Taxi/ } \\
\text { Auto drivers/cleaners }\end{array}$ & 88 & 3 & - & - & 88 & 3 & \\
\hline & Industrial workers & 124 & 3 & 119 & - & 243 & 3 & \\
\hline & Hotel Staff & 36 & - & 10 & 1 & 46 & 1 & \\
\hline & Service class & 281 & 8 & 104 & - & 385 & 8 & \\
\hline & Business Class & 209 & 5 & 208 & - & 417 & 5 & \\
\hline & Unemployed & 83 & - & 100 & 1 & 183 & 1 & \\
\hline & Student & 156 & 3 & 58 & - & 214 & 3 & \\
\hline & Housewife & & - & 1149 & 14 & 1149 & 14 & \\
\hline \multirow[t]{2}{*}{ Migration } & Migrant & 429 & 8 & 537 & - & 966 & 8 & \multirow[t]{2}{*}{$\begin{array}{l}X 2(1)=0.633 \\
P=0.426\end{array}$} \\
\hline & Non - Migrant & 926 & 16 & 2086 & 18 & 3012 & 34 & \\
\hline \multirow{6}{*}{ STDs } & Genital Ulcers & 363 & 7 & 658 & 8 & 1021 & 15 & \multirow[t]{6}{*}{$\begin{array}{l}X 2(5)=0.2360 \\
p=0.501\end{array}$} \\
\hline & Urethral Discharge & 583 & 10 & - & - & 583 & 10 & \\
\hline & Cervical Discharge & - & - & 1296 & 7 & 1296 & 7 & \\
\hline & Genital ulcers \& UD & 210 & 4 & - & - & 210 & 4 & \\
\hline & Genital ulcers \& CD & & - & 281 & - & 281 & - & \\
\hline & Genital Warts & 199 & 3 & 388 & 3 & 587 & 6 & \\
\hline
\end{tabular}

was noted. The fifth year showed an increase 18/1315 $(1.36 \%)$ in HIV infection. In the sixth year and seventh year, once again a decrease $6 / 873(0.68 \%)$ and $4 / 897$ $(0.44 \%)$, respectively was observed. The VDRL reactivity observed during the seven years of screening revealed that the range varied between $4.5 \%$ to $8 \%$ but a sudden rise in the case detection rates from $52 / 873$ $(6 \%)$ to $115 / 897(12.82 \%)$ is alarming. The fluctuation in the trend of HIV infection is significant but does not reveal any major causative factor. Out of 3978 coded sera samples, 42(1.06\%) were HIV-positive and 322 $(8.09 \%)$ were VDRL reactive. The difference in the proportion of HIV-positivity and VDRL-reactivity was found statistically significant $(\mathrm{Z}=14.88, \mathrm{p}<0.001$ ). Analysis with Chi-Square (trend) showed that there is a declining trend in HIV-positivity [ $\chi^{2}=10.168, \mathrm{p}<$ $0.001]$ and an increasing trend of VDRL-reactivity $\left[\chi^{2}\right.$ $=12.353, \mathrm{p}<0.0004]$ which could be due to more number of VDRL reactives in the VII year. If we reanalyse the VDRL data excluding the outlier in the VII year, even then it shows a slightly increasing trend in VDRL reactivity, which is statistically insignificant $\left[\chi^{2}\right.$ $=0.033, \mathrm{p}=0.86$ for VDRL $]$. The results suggest that the patients attending the Sentinel Sites were having 
Am. J. Infect. Dis., 2 (1): 28-35, 2006

Table 3: Represents the HIV prevalence levels, State wise: 2003

\begin{tabular}{|c|c|c|c|c|}
\hline S.No. & Name of State / UT* & Number of sites in 2003 & $\begin{array}{l}\text { HIV prevalence } 2002(\%) \\
\text { [ } 384 \text { sites ] }\end{array}$ & $\begin{array}{c}\text { HIV prevalence } 2003(\%) \\
\text { [ } 455 \text { sites ] }\end{array}$ \\
\hline \multirow[t]{2}{*}{1.} & Andhra Pradesh & STD 8 & 30.40 & 19.60 \\
\hline & & ANC 14 & 1.25 & 1.25 \\
\hline \multirow[t]{2}{*}{2.} & Arunachal Pradesh & STD 4 & 0.00 & 0.00 \\
\hline & & ANC 2 & 0.00 & 0.38 \\
\hline \multirow[t]{2}{*}{3.} & Assam & STD 5 & 0.75 & 1.20 \\
\hline & & ANC 4 & 0.00 & 0.00 \\
\hline \multirow[t]{2}{*}{4.} & Bihar & STD 8 & 1.60 & 0.40 \\
\hline & & ANC 7 & 0.25 & 0.00 \\
\hline 5. & Chattisgarh & STD 3 & 0.80 & 2.27 \\
\hline & & ANC 5 & 0.25 & 1.00 \\
\hline 6. & Delhi & STD 4 & 3.23 & 7.20 \\
\hline & & ANC 4 & 0.25 & 0.13 \\
\hline & & IDU 1 & 7.20 & - \\
\hline 7. & Goa & STD 2 & 11.29 & 14.30 \\
\hline & & ANC 2 & 1.38 & 0.50 \\
\hline & & CSW 1 & 24.00 & 30.1 \\
\hline 8. & Gujarat & STD 8 & 6.17 & 4.50 \\
\hline & & ANC 8 & 0.38 & 0.40 \\
\hline 9. & Haryana & STD 5 & 1.14 & 1.20 \\
\hline & & ANC 4 & 0.38 & 0.25 \\
\hline 10. & Himachal Pradesh & STD 5 & 0.40 & 0.40 \\
\hline & & ANC 7 & 0.00 & 0.00 \\
\hline 11. & Jammu \& Kashmir & STD 2 & 0.95 & 1.86 \\
\hline & & ANC 3 & 0.08 & 0.00 \\
\hline 12. & Jharkhand & STD 3 & 0.13 & 0.13 \\
\hline & & ANC 6 & 0.00 & 0.00 \\
\hline 13. & Karnataka & STD 7 & 13.60 & 10.40 \\
\hline & & ANC 10 & 1.75 & 1.25 \\
\hline & & IDU 1 & 2.26 & 2.80 \\
\hline 14. & Kerala & STD 4 & 2.45 & 4.00 \\
\hline & & ANC 4 & 0.38 & 0.33 \\
\hline 15. & Madhya Pradesh & STD 10 & 2.35 & 1.20 \\
\hline & & ANC 13 & 0.00 & 0.00 \\
\hline 16. & Maharashtra & STD 9 & 7.60 & 10.00 \\
\hline & & ANC 14 & 1.25 & 1.25 \\
\hline 17. & Mumbai & STD 3 & 14.84 & 18.40 \\
\hline & & ANC 6 & 0.75 & 1.25 \\
\hline & & IDU 1 & 39.42 & 24.80 \\
\hline & & MSM 1 & 16.80 & 18.80 \\
\hline & & CSW 1 & 54.50 & 54.29 \\
\hline 18. & Manipur & IDU 3 & 39.06 & 24.40 \\
\hline & & STD 2 & 9.60 & 13.00 \\
\hline & & ANC 10 & 1.12 & 1.25 \\
\hline 19. & Meghalaya & IDU 1 & 0.00 & 0.40 \\
\hline & & STD 2 & 0.90 & 0.25 \\
\hline & & ANC 2 & 0.00 & 0.00 \\
\hline 20. & Mizoram & IDU 1 & 1.60 & 4.00 \\
\hline & & STD 2 & 2.60 & 3.80 \\
\hline & & ANC 3 & 1.50 & 1.38 \\
\hline 21. & Nagaland & IDU 3 & 10.28 & 13.86 \\
\hline & & STD 1 & 2.42 & 0.90 \\
\hline & & ANC 4 & 1.25 & 1.25 \\
\hline 22. & Orissa & STD 8 & 0.80 & 2.40 \\
\hline & & ANC 4 & 0.25 & 0.00 \\
\hline 23. & Punjab & STD 3 & 1.60 & 1.60 \\
\hline & & ANC 4 & 0.49 & 0.00 \\
\hline 24. & Rajasthan & STD 7 & 6.00 & 3.70 \\
\hline & & ANC 6 & 0.50 & 0.13 \\
\hline 25. & Sikkim & STD 1 & 0.00 & 0.00 \\
\hline & & ANC 2 & 0.13 & 0.13 \\
\hline 26. & Tamil Nadu & STD 11 & 14.7 & 9.20 \\
\hline & & ANC 10 & 0.88 & 0.75 \\
\hline & & IDU 1 & 33.80 & 63.6 \\
\hline & & MSM 2 & 2.40 & 4.40 \\
\hline 27. & Tripura & STD 2 & 1.40 & 0.00 \\
\hline & & ANC 1 & 0.00 & 0.00 \\
\hline 28. & Uttar Pradesh & STD 17 & 0.80 & 0.55 \\
\hline & & ANC 17 & 0.25 & 0.00 \\
\hline 29. & Uttaranchal & STD 4 & 0.26 & 0.00 \\
\hline & & ANC 3 & 0.23 & 0.00 \\
\hline 30. & West Bengal & STD 8 & 0.47 & 1.45 \\
\hline & & ANC 9 & 0.00 & 0.50 \\
\hline & & IDU 1 & 1.50 & 2.70 \\
\hline $31 . *$ & Andaman\&Nicobar Islands & STD 2 & 2.60 & 1.60 \\
\hline & & ANC 3 & 0.00 & 0.50 \\
\hline $32 . *$ & Chandigarh & STD 2 & 0.80 & 1.66 \\
\hline & & ANC 1 & 0.25 & 0.50 \\
\hline 33.* & Dadar \& Nagar Haveli & STD 0 & - & - \\
\hline & & ANC 1 & 0.22 & 0.13 \\
\hline $34 . *$ & Daman \& Diu & STD 0 & - & - \\
\hline & & ANC 2 & 0.22 & 0.50 \\
\hline $35 . *$ & Lakshadweep & STD 1 & 0.00 & 0.00 \\
\hline & & ANC 2 & 0.00 & 0.00 \\
\hline $36 . *$ & Pondicherry & STD 3 & 2.02 & 2.60 \\
\hline & & ANC 2 & 0.25 & 0.13 \\
\hline
\end{tabular}

* UT - denotes Union Territories

* Source NACO website : nacoonline.org

* V prevalence values in States with more than 3 sites are Median values, while in States/UTs with 3 or less than 3 sites, the values are Mean values.

* Sites with $75 \%$ coverage of desired sample size (STD : 250 \& ANC : 400) are included for analysis. 
both HIV and STDs. The HIV-positivity was $1.49 \%$ (26/1740) and VDRL reactivity was 9.5\% (165/1740) among the STD clinic attendees. 0.7\% (7/1038) HIVpositivity was observed among Gyn.\& Obs. clinic attendees whereas VDRL reactivity was $6.65 \%$ (69/1038). $0.92 \%$ (11/1200) HIV-positivity and 7.3\% (88/1200) VDRL reactivity was observed among attendees of ANC clinic, of one district, Etawah. HIVpositivity was $1.11 \%$ (44/3978) whereas that of VDRL reactivity was $8.09 \%$ (322/3978). Positive VDRLs were confirmed by a Treponema specific test, INNO-LIA Syphilis (Innogenetics NV, Ghent, Belgium) ${ }^{[5]}$. The proportion of biological false positives was $12 \%$. Table 2 depicts the socio-demographic characteristics, profile of different STDs and HIV status of 3978 clients attending the sentinel sites. $18(0.68 \%)$ of the female and $24(1.77 \%)$ of the male clients were HIV-positive. The proportion of HIV-positivity in male is more than double that of the female clients $(\mathrm{p}=0.002)$. Among the attendees of sentinel sites, $7(1.23 \%)$ of the clients below the age of 20 years were HIV-positive. 11 $(0.54 \%)$ of the clients between the age group of 21-29 years, were HIV-positive. 19 (1.67\%) in the age group of 30-44 years were HIV-positive. And $5(1.98 \%)$ of the clients above 45 years of age were HIV-positive. The age of the clients was found to be associated with HIV positivity, the percentage of HIV positive was highest (1.94\%) in the clients whose age was more then 45 years followed by client of 30-34 and up to 20 years of age. And it was lowest (0.54\%) in the 21-29 age group. This difference in percentage of HIV positivity in different age groups was statistically significant $(\mathrm{p}=$ $0.01) .1 .06 \%$ of married clients were HIV-positive while $1.04 \%$ of unmarried clients were HIV-positive. Of the 3978 clients, attendance of patients at the STD clinics from urban locality was more in comparison to rural locality. HIV-positive Urban attendees, were more, $31(1.16 \%)$ in comparison to rural attendees, 11 $(0.85 \%)$. The present study shows that the locality does not play any role in acquiring HIV infection since there is no significant difference in HIV-positive clients living in rural and urban locality. Among the patients attending the sentinel sites, $11(0.84 \%)$ of illiterate clients were HIV-positive. 5 (0.68\%) who had studied upto primary school were HIV-positive. 14 (1.12\%) of the clinic attendees who had an education of high school were HIV-positive. Further, 12 (1.75\%) graduates were HIV-positive. The percentage of HIVpositive clients vary in different educational groups, it was lowest in those who had primary education and highest in graduates. Labourers, mainly migrant, were the ones having the HIV and maximum number of STDs. Among the clients, majority were agricultural and unskilled workers 1253 (31.49\%) followed by housewives 1149 (28.88\%), business class 417 $(10.48 \%)$, service class 385 (9.67\%), students 214 $(5.37 \%)$, industrial workers $243(6.10 \%)$, unemployed
$183(4.60 \%)$, drivers $88(2.21 \%)$ and Hotel staff 46 $(1.15 \%)$. Among these groups, the percentage of HIVpositivity was as follows, $1(0.55 \%)$ in unemployed agricultural and unskilled workers, $4(0.32 \%)$, students $3(1.40 \%)$, housewives $14(1.22 \%)$, business class 5 $(1.20 \%)$ and service class $8(2.08 \%)$. The percentage of HIV-positive clients varied from $0.32 \%$ to $3.41 \%$ in different occupational groups which was statistically significant $(\mathrm{p}=0.033)$. Those who were staying at one place for more than 6 months were regarded as nonmigrants. Among the non-migrants, $34(1.13 \%)$ were HIV-positive. Only $8(0.83 \%)$ of the migrant population them were HIV-positive in this group. The percentage of HIV-positives was high among non-migrants in comparison to migrant clients. The chief presenting symptoms at the time of visit to the clinic were genital warts, genital ulcers, urethral discharge / cervical discharge and genital ulcers and urethral discharge/cervical discharge. Among males, 1.93\% having genital ulcers, $1.71 \%$ with urethral discharge / cervical discharge, $1.90 \%$ with genital ulcers and urethral discharge / cervical discharge and $1.50 \%$ with genital warts were HIV-positive. Among females, $1.22 \%$ having genital ulcers, $0.541 \%$ with cervical discharge and $0.77 \%$ with genital warts were HIVpositive. The percentage of HIV-positives in attendees of Sentinel sites vary from $0.8 \%$ to $1.47 \%$. It was lowest $0.81 \%$ in the clients who had symptoms of genital ulcers and urethral discharge/ cervical discharge and highest $1.47 \%$ in clients with symptoms of genital ulcers followed by $0.91 \%$ with urethral discharge/ cervical discharge and $1.02 \%$ with genital warts. Of these, $42(1.06 \%)$ were HIV-positive and $322(8.09 \%)$ were VDRL reactive. This suggests that a large percentage is affected by the STDs. Statistical analysis of the results revealed that while some of the variables, viz., sex, age-group and occupation were significant factors in the HIV-positivity, others like literacy status, locality, migration and even the presence of different STDs were not found to influence the HIV-positivity, significantly.

\section{DISCUSSION}

Sentinel surveillance is conducted by NACO in different States of India, every year. Table 3 shows the HIV prevalence levels in the States of India where Uttar Pradesh is a low-prevalence state for HIV infection. In our study, we have observed that there is a decline in HIV-positivity and an increasing trend of VDRLreactivity among the attendees of STD, Gyn.\&Obs. and ANC clinics. HIV sentinel data of seven rounds revealed that the prevalence of HIV infection is less, i.e., 42 /3978 (1.06\%) among the STD clinic attendees whereas that of Syphilis is high, 322 / 3978 (8.09\%). Over time, prevalence of HIV infection declines but that of Syphilis increases. This could be due to more 
number of VDRL reactives in the VII year. The VDRL reactivity observed during the seven years of screening revealed that the range varied between $4.5 \%$ to $8 \%$ but a sudden rise in the case detection rates from 52/873 $(6 \%)$ to $115 / 897(12.82 \%)$ is alarming. An increase in reported STD rates in the initial years is a positive indicator of enhanced early detection of STDs. The rates declined in subsequent years. The fluctuation in the trend of HIV infection is significant but does not reveal any major causative factor. Sentinel surveillance plays a key role in HIV prevention. HIV sentinel surveillance is an epidemiological tool by which samples of pre-designed sample size are collected over time, from among the identified risk groups known as sentinel groups. This sample size represents the larger group with similar risk and other characteristics. Surveillance data serves to supplement the data derived from HIV sentinel surveillance in monitoring the spread of the HIV epidemic and could contribute to the planning of hospital and home/community based care for AIDS patients through NACO. Although the surveillance is unlinked and anonymous, a retrospective Statistical analysis of the data revealed that sex, agegroup and occupation were significant factors in the HIV-positivity. The results reveal that patients attending the STD, Gyn.\&Obs. and ANC clinics harbour HIV infection which would otherwise remain undiagnosed in the absence of screening. Further, they were unaware of the underlying co-infection because this was an unlinked anonymous testing of coded sera samples. Many studies in India and abroad have been reported by several authors. These studies, however, indicated the varying rates of HIV infection among STD patients, the common STDs and different prevention strategies ${ }^{[6-8]}$. Mateo et al. ${ }^{[9]}$ reported that HIV/AIDS has not yet caused a widespread epidemic in the Phillipines. Rates in all the ususal risk groups have remained below $1 \%$. In a few areas, only $1-2 \%$ in some risk groups have been reported. Law et al. ${ }^{[10]}$ analysed and mapped the distribution of 4 STDs. STD surveillance data in Wake County, North Carolina in 2000 was used to analyse and map STD rates. Spatial heterogeneity within STD suggests STD specific prevention strategies should not be targeted uniformily. Geostatistical techniques are objective, population level approaches to spatial analysis and mapping that can be used to visualize disease patterns and identify emerging outbreaks. Bolu et al. ${ }^{[11]}$ conducted a subset analysis of data from 1993-1996 during a randomized, controlled trial (Project RESPECT). 4328 participants from 5 public U.S. STD clinics were assigned to enhanced counseling, brief counseling or educational messages. They found that HIV/STD prevention counseling ( brief or enhanced ) resulted in fewer STDs than education messages. Hightow et al. ${ }^{[12,13]}$ assessed the extent of and characteristics associated with repeat HIV testing in persons presenting to STD clinics. 101 new diagnosed HIV-infected and 411 matched HIV-uninfected subjects in a STD clinic, over a 5-year period in a southeastern United States were followed-up. They found that repeat HIV testing is common among patients receiving services at a STD clinic. Bertolli et al. ${ }^{[14]}$ examined the data from national surveillance systems to describe the spread of HIV/AIDS and prevalence of HIV-related risk behaviours among American Indian/Alaska native (AI/AN) people. The data indicated that AI/AN youth and women are particularly vulnerable to continued spread of HIV infection. Gottileb et al. ${ }^{[15]}$ determined the seroincidence of HSV-2 among 1766 patients attending STD clinics enrolled in a randomized, controlled trial of HIV/STD risk-reduction counseling. They observed that interventions more specifically tailored to genital herpes may be useful and are important focus of future studies. Diaz et al. ${ }^{[16]}$ evaluated the Abott Determine Rapid Syphilis TP assay using stored serum specimens who tested TPHA positive in Rio de Janeiro, Brazil. The TP assay has high sensitivity and high specificity and inter-reader variability, indicating that it may be easily used in resource poor settings without laboratory facilities. Smith et $a l .{ }^{[17]}$ reported that economic factors are strongly associated with STDs (Chlamydia and/or gonorrhoea) risk in women in rural Haiti. Marrazzo et $a l .{ }^{[18]}$ reported that number of primary or secondary syphilis have increased in New York City from 130 to 434 during 1999 to 2002 and majority of new cases occur in men, who have sex with men. Client-centered counseling may be successful in reducing risky behaviors and the transmission of STDs. Erbelding et $a l .{ }^{[19]}$ analysed data on 31,777 STD clinic patients undergoing HIV testing between 1994-1998 who tested HIV-negative and observed that HIV testing is routinely performed in STD clinics, but many do not follow up for results. Operational changes to improve test results notification, or enhanced counseling at the initial test visit, particularly focusing on young men with gonorrhoea, may optimize prevention outcomes in this high risk population. Klausner et al. ${ }^{[20]}$ advocated that physicians who care for patients with HIV infection should be familiar with recent guidelines recommending routine risk assessment and STD screening in these patients. STDs can impact the clinical management of patients infected with HIV by increasing both viral load and HIV infectiousness. Sullivan et al. ${ }^{[21]}$ conducted a prevalence survey on pregnant women in Apia, Samoa utilizing 2 prenatal hospital clinics. They observed that there is no routine prenatal screening for STDs and HIV during pregnancy in Samoa. The lack of inexpensive, reliable field diagnostics remain a barrier to sustainable STD control programmes for pregnant women living in developing countries. Joyee et al. ${ }^{[22]}$ reported high infection rate for Chlamydia trachomatis in 143 symptomatic patients with STDs attending the Sex.Transm.Dis. Institute in Chennai, India. They feel specific diagnostic tests need to be recommended for routine inclusion in the STD 
diagnosis to facilitate risk reduction of HIV infection in STD patients. Shepherd et al. ${ }^{[23]}$ studied the systematic disparities in rates of HIV incidence by assessing the socioeconomic status among $2260 \mathrm{HIV}$-uninfected men attending the 3 STD clinics in Pune, India from 19932000. The study provided evidence that by enhancing access to treatment and interventions that include counseling, education and provision of condoms, rates of HIV incidence could be lessened considerably. Our study and other studies emphasize the need for routine HIV screening of patients attending the STD, Gyn.\&Obs. and ANC clinics. In STD clinics, integrating risk-based screening into routine clinic services is an efficient way to identify HIV-infected persons. There is a need, therefore, to support an approach of targetted screening of HIV infections, integrate HIV testing and referral services into the existing STD prevention or treatment services.

\section{ACKNOWLEDGEMENTS}

This study was supported by funds from the UP State AIDS Control Society (UPSACS), Lucknow, a State body of the National AIDS Control Organisation (NACO), New Delhi. The authors thank the Medical Officers and Staff of OPD of the Sentinel Sites at Agra, Etawah and Farrukhabad and Mr.P.N.Sharma of the VCCTC for their help in the study.

\section{REFERENCES}

1. DePaola, L.G. and W.M. Carpenter, 2002. Bloodborne pathogens: Current concepts. Compend. Contin. Educ. Dent., 23: 207-210.

2. Erbelding, E.J., S.E. Chung, M.L. Kamb, K.L. Irwin and A.M. Rompalo, 2003. New sexually transmitted diseases in HIV-infected patients: Markers for ongoing HIV transmission behaviour. J. Acquir. Immun. Defic. Syndr., 33: 247-252.

3. Directorate Health Systems Research and Epidemiology, 2001. Summary Report: National sero-prevalence survey of women attending public antenatal clinics in South Africa. Pretoria: Department of Health.

4. Manual of the National Annual Sentinel Surveillance for HIV infections, $1^{\text {st }}-7^{\text {th }}$ round.

5. Hagedorn, H.J., A. K. Hagedorn, K.De Bosschere, F. Hulstaert, H. Pottel and M. Zrein, 2002. Evaluation of INNO-LIA syphilis assay as a confirmatory test for syphilis. J. Clin. Microbiol., 40: 973-978.

6. Golden, M.R., M. Hogben, H.H. Handsfield, J.S. St.Lawrence, J.J. Potterat and K.K. Holmes, 2003. Partner notification for HIV and STD in the United States: Low coverage for gonorrhoea, chlamydial infection and HIV. Sex. Transm. Dis., 30: 490-496.
7. Pinkerton, S.D., P.M. Layde, W. DiFranceisso and H.W. Chesson, 2003. All STDs are not created equal: An analysis of the differential effects of sexual behaviour changes on different STDs. Int. J. STD. AIDS, 14: 320-328.

8. Tao, G., B.M. Branson, L.A. Anderson and M. Macaluso, 2003. Do physicians provide counselling with HIV and STD testing at physician offices or hospital outpatient departments ? AIDS, 17: 1234-1237.

9. Mateo, R.Jr., J.N.Jr. Sarol and R. Poblete, 2004. HIV/AIDS in the Phillipines. AIDS Educ.Prev., 16: 43-52.

10. Law, D.C., M.L. Serre, G. Christakos, P.A. Leone and W.C. Miller, 2004. Spatial analysis and mapping of sexually transmitted diseases to optimize intervention and prevention strategies. Sex. Trans. Infect., 80: 294-299.

11. Bolu, O.O., C. Lindsey, M.L. Kamb, C. Kent, J. Zenilman, J.M. Douglas, C.K. Malotte, J. Rogers and T.A. Peterman, 2004. Project RESPECT Study group. Is HIV/sexually transmitted disease prevention counseling effective among vulnerable populations? A subset analysis of data collected for a randomized, controlled trial evaluating counseling efficacy (Project RESPECT). Sex. Trans. Dis., 8: 469-474.

12. Hightow, L.B., W.C. Miller, P.A. Leone, D. Wohl, M. Smurzynski and A.H. Kaplan, 2003. Failure to return for HIV post-test counselling in an STD clinic population. AIDS Edu. Prev., 3: 282-290.

13. Hightow, L.B., W.C. Miller, P.A. Leone, D. Wohl, M. Smurzynski and A.H. Kaplan, 2003. Predictors of repeat testing and HIV seroconversion in a sexually transmitted diseases clinic population. Sex. Trans. Dis., 31: 455-459.

14. Bertolli, J., A.D. McNaghten, M. Campsmith, L.M. Lee, R. Leman, R.T. Bryan and J.W. Buehler, 2004. Surveillance systems monitoring HIV/AIDS and HIV risk behaviours among American Indians and Alaska Natives. AIDS Educ. Prev., 16: 218237.

15. Gottileb, S.L., J.M.Jr. Douglas, M. Foster, D.S. Schmid, D.R. Newman, A.E. Baron, G. Bolan, M. Iatesta, C.K. Malotte, J. Zenilman, M. Fishbein, T.A. Peterman and M.L. Kamb, 2004. Project RESPECT Study Group. Incidence of herpes simplex virus type 2 infection in 5 sexually transmitted diseases (STD) clinics and the effect of HIV/STD risk-reduction counselling. J. Inf. Dis., 190: 1059-1067.

16. Diaz, T., M.G. Almeida, I. Georg, S.C. Maia, R.V. De Souza and L.E. Markowitz, 2004. Evaluation of the determine rapid syphilis TP assay using sera. Clin. Diagn. Lab. Immunol., 11: 98-101. 
17. Smith, F.M.C., W. Lambert, J.M. Singler, S.P. Koenig, F. Leandre, P. Nevil, D. Bertrand, M.S. Claude, J. Bertrand, J.J. Salazar, M. Louissaint, L. Joanis and P.E. Farmer, 2003. Prevalence and risk factors of STDs in rural Haiti: Implications in policy and programming in resource-poor settings. Int. J. STD. AIDS., 14: 848-853.

18. Marrazzo, J., 2004. Sexually transmitted diseases in the HIV care setting: What's really going on down there? J. Top. HIV Med., 12: 57-60.

19. Erbelding, E.J., S. Chung and J.M. Zenilman, 2004. Following-up for HIV test results: What limits return in an STD clinic population? Int. J. STD.AIDS, 15: 29-32.

20. Klausner, J.D. and C.K. Kent, 2004. HIV and sexually transmitted diseases. Latest views on synergy, treatment and screening. Postgrad. Med., 115: 79-84.
21. Sullivan, E.A., S. Koro, S. Tabrizi, J. Kaldor, G. Poumerol, S. Chen, M. O'Leary and S.M. Garland, 2004. Prevalence of sexually transmitted diseases and human immunodeficiency virus among women attending prenatal services in Apia, Samoa. Int. J. STD.AIDS, 15: 116-119.

22. Joyee, A.G., S.P. Thyagarajan, B. Sowmya, C. Venkatesan and M. Ganapathy, 2003. Need for specific and routine strategy for the diagnosis of genital chlamydial infection among patients with sexually transmitted diseases in India. Ind. J. Med. Res., 118: 152-157.

23. Shepherd, M.E., R.R. Gangakhedkar, S. Sahay, S.J. Reynolds, M.V. Ghate, A.R. Risbud, R.S. Paranjpe, R.C. Bollinger and S.M. Mehendale, 2003. Incident HIV infection among men attending STD clinics in Pune, India: Pathways to disparity and interventions to enhance equity. J. Health Popul. Nutr., 21: 251-263. 